\title{
Rifampicin therapy in shigellosis in infancy
}

\author{
YEHEZKEL NAVEH, PAUL STRAHOVSKY, AND ABRAHAM FRIEDMAN \\ From Department of Paediatrics ' $B$ ', Rambam Medical Centre, Abba Khoushi Medical School, and \\ Shabtai Levy Children's Home and Nursery, Haifa, Israel
}

SUMMARY Eleven infants aged 1-2 years suffering from shigellosis associated with Shigella flexneri type 6 were treated with rifampicin. All were initially treated with antimicrobial drugs to which Sh. flexneri was shown to be sensitive, but without effect. Rifampicin was effective in curing gastrointestinal symptoms and eradicating the bacilli in all infants in 5 days. The drug was given in a dose of $10-12 \mathrm{mg} / \mathrm{kg}$ per day divided into two equal parts, for 7 days. No untoward side effects were observed. Our experience should encourage the use of this agent in controlling outbreaks of shigellosis and in curing resistant Shigella spp. infections where other antimicrobial agents prove to be inefficient.

Shigellosis continues to be a public health problem especially among institutionalized infants (DuPont et al., 1970). Antimicrobial therapy and isolation frequently fail to eradicate outbreaks caused by Shigella species resistant to first-choice current drugs.

Viewpoints differ on the most appropriate course of therapy for shigellosis. There have been many reports concerning the efficacy and possible hazards of specific antibiotic therapy. Weissman et al. (1974) summarized guidelines for chemotherapy for shigellosis, concluding that sensitive shigella resulting in severe or moderate disease may be treated or not by antimicrobial drugs. Outbreaks of shigellosis are frequent and may prove disastrous, causing anxiety to paediatricians responsible for nursery and paediatric wards. Treatment of infants with antimicrobial drugs is mostly justified.

Recently we treated 11 infants in a nursery suffering from Shigella flexneri with rifampicin after other antimicrobial drugs had proved ineffective.

\section{Material}

Eleven infants aged 1-2 years (Table) suffering from bacillary dysentery due to $S h$. flexneri type 6 were treated with rifampicin $10-12 \mathrm{mg} / \mathrm{kg}$ per day divided into 2 equal parts for 7 days. Cross-infection with Sh. flexneri occurred in all 11 in an infant nursery, and all suffered intermittently or continuously from fever and dysentery for 1 to 4 months. Stool cultures yielded a growth of Sh. flexneri type 6 sensitive to nitrofurantoin, chloramphenicol, ampicillin sodium,

Received 5 May 1977 trimethoprim-sulphamethoxazole, and rifampicin. 9 infants were put on several courses of antimicrobial drugs to which Sh. flexneri was shown to be sensitive, before rifampicin therapy was tried. Cases 7 and 10 had only one course each of co-trimoxazole and Case 9 one course of furazolidone before rifampicin therapy. All drugs were given orally.

\section{Results}

The diarrhoea and fever responded dramatically in all the infants after 3-5 days of rifampicin therapy. Administration for 7 days ensured eradication of $S h$. flexneri. All stool cultures taken during a follow-up period of 1 month remained negative. No untoward side effects were observed.

\section{Discussion}

Failure of furazolidone therapy was noted by Elliott et al. (1963) and Haltalin and Nelson (1972). Results in 8 of our patients were similar to theirs. Co-trimoxazole was found to be superior to furazolidone in treating shigellosis (Lexomboon et al., 1972). Nelson et al. (1976) found co-trimoxazole to be the best available drug for treatment of infection with shigella resistant to ampicillin and other antibiotics. Unfortunately our results with co-trimoxazole were disappointing in 10 patients. Treatment with chloramphenicol (Case 1) and ampicillin (Case 5) was disappointing too.

The dramatic results of treatment in our cases leave no doubt of the effectiveness of rifampicin in the treatment of resistant shigella infection. Two of 
Table Clinical data of the patients

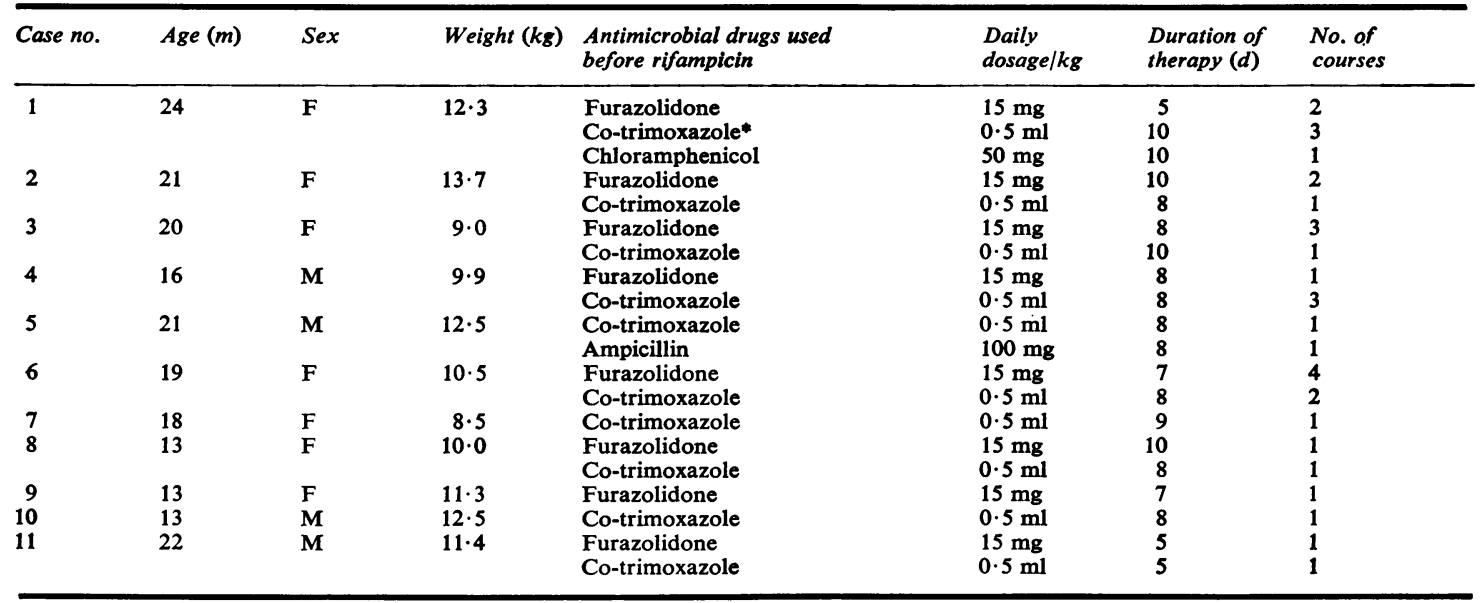

*1 ml co-trimoxazole contains $8 \mathrm{mg}$ trimethoprim and $40 \mathrm{mg}$ sulphamethoxazole.

us had successfully tried rifampicin in Sh. flexneri septicaemia (Naveh and Friedman, 1973) and in $E$. coli gastroenteritis (Naveh and Friedman, 1974). Review of published reports yielded only two Japanese papers reporting the efficacy of rifampicin in treatment of shigellosis (Nakazawa and Sato, 1969; Osada et al., 1972). Osada et al. (1972) proved that rifampicin was superior to kanamycin for bacillary dysentery using cynomolgus monkeys experimentally infected with Sh. flexneri type $2 \mathrm{a}$.

The recommended daily dosage is $10 \mathrm{mg} / \mathrm{kg}$ in ordinary infections, and $20 \mathrm{mg} / \mathrm{kg}$ in more severe infections (Scarzella, 1969). Rifampicin has the advantage of ease of administration, since it is given orally in twice-daily doses, and according to Durand (1969) a single daily dose may suffice.

The efficacy of this bactericidal drug, its tolerance by small infants, its excellent absorption by the inflamed intestine, and its broad spectrum makes it a useful alternative preparation in drug-resistant shigella infection in which antimicrobial therapy is indicated and/or rapid eradication of shigella is imperative from the public health point of view.

We thank Dr. Betty Kretzer of the Central Laboratory of Bacteriology, General Labourer Sick Fund, and Mrs. Ruth Meissner, head nurse of Shabtai Levy Children's Home and Nursery, for help.

\section{References}

DuPont, H. L., Gangarosa, E. J., Reller, L. B., Woodward, W. E., Armstrong, R. W., Hammond, J., Glaser, K., and Morris, G. K. (1970). Shigellosis in custodial institutions. American Journal of Epidemiology, 92, 172-179.
Durand, P. (1969). La nostra esperienza sull'impiego pediatrico della rifampicina. Archivio E. Maragliano di Patologia e Clinica, 25, 413-415.

Elliott, R. B., Maxwell, G. M., and Kneebone, G. M. (1963). An appraisal of antibacterial therapy in childhood gastroenteritis. Medical Journal of Australia, 2, 579-582.

Haltalin, K. C., and Nelson, J. D. (1972). Failure of furazolidone therapy in shigellosis. American Journal of Diseases of Children, 123, 40-44.

Lexomboon, U., Mansuwan, P., Duangmani, C., Benjadol, P., and M'c Minn, M. T. (1972). Clinical evaluation of co-trimoxazole and furazolidone in treatment of shigellosis in children. British Medical Journal, 3, 23-26.

Nakazawa, S., and Sato, H. (1969). Experimental and clinical evaluation of rifampicin in bacillary dysentery. Journal of the Japanese Association of Infectious Diseases, 43, 184-189.

Naveh, Y., and Friedman, A. (1973). Rifampicin therapy in Gram-negative bacteraemia in infancy. Archives of Disease in Childhood, 48, 967-969.

Naveh, Y., and Friedman, A. (1974). Rifampicin therapy in Escherichia coli gastroenteritis. Postgraduate Medical Journal, 50, 707-709.

Nelson, J. D., Kusmiesz, H., and Jackson, L. H. (1976). Comparison of trimethoprim-sulfamethoxazole and ampicillin therapy for shigellosis in ambulatory patients. Journal of Pediatrics, 89, 491-493.

Osada, Y., Nakajo, M., Inaba, M., Une, T., Ogawa, H., Oshima, Y., Takasaka, M., Honjo, S., and Imaizumi, K. (1972). Chemotherapeutic evaluation of rifampicin to experimental bacillary dysentery in cynomolgus monkeys. Japanese Journal of Microbiology, 16, 275-285.

Scarzella, M. (1969). La rifampicina nella pratica pediatrica. Minerva Medica, 60, 4838-4839.

Weissman, J. B., Gangarosa, E. J., Dupont, H. L., Nelson, J. D., and Haltalin, K. C. (1974). Shigellosis. To treat or not to treat? Journal of the American Medical Association, 229, 1215-1216.

Correspondence to Dr. Y. Naveh, Department of Paediatrics 'B', Rambam Medical Centre, Haifa, Israel. 